\title{
Erratum
}

\section{Erratum to "Analytical characterization of some synthetic cannabinoids, derivatives of indole-3-carboxylic acid" [Forensic Sci. Int. 232 (2013) 1-10]}

\author{
Vadim Shevyrin $^{\mathrm{a}}$, Vladimir Melkozerov ${ }^{\mathrm{b}}$, Alexander Nevero ${ }^{\mathrm{c}}$, Oleg Eltsov ${ }^{\mathrm{a}}$, \\ Yuri Shafran ${ }^{\mathrm{a}, \mathrm{d}, *}$ \\ ${ }^{a}$ Ural Federal University, Institute of Chemistry and Technology, 19 Mira Str., 620002 Ekaterinburg, Russian Federation \\ ${ }^{\mathrm{b}}$ Expert and Criminalistic Center, Main Agency of the Ministry of the Interior of the Russian Federation, Sverdlovsk Region Branch, 17 Lenina Avenue, 620014 \\ Ekaterinburg, Russian Federation \\ ' State Committee of Forensic Expertises of Republic of Belarus, 43 Kalvariyskaya Str., 220073 Minsk, Belarus \\ ${ }^{\mathrm{d}}$ TOSLab. Ltd., Bldg. 1, 5 Initsiativnaia Str., 121357 Moscow, Russian Federation
}

The publisher regrets that Fig. 5 was omitted from the downloadable and printed version of this paper.

Please find Fig. 5 below. It can also be found within the online version of the article, DOI at the foot of this page.

The publisher would like to apologise for any inconvenience caused.

DOI of original article: http://dx.doi.org/10.1016/j.forsciint.2013.06.011

* Corresponding author at: Ural Federal University, Institute of Chemistry and Technology, 19 Mira Street, 620002 Ekaterinburg, Russian Federation. Tel.: +7 343 375 4135 ; fax: +7 3433754135

E-mail addresses: vadim.shevyrin@gmail.com (V. Shevyrin), experts@ru66.ru (V. Melkozerov), a.s.nevero@gmail.com (A. Nevero), oleg-eltsov@yandex.ru (O. Eltsov), yu.m.shafran@ustu.ru, yuri.shafran@toslab.com (Yu. Shafran). 

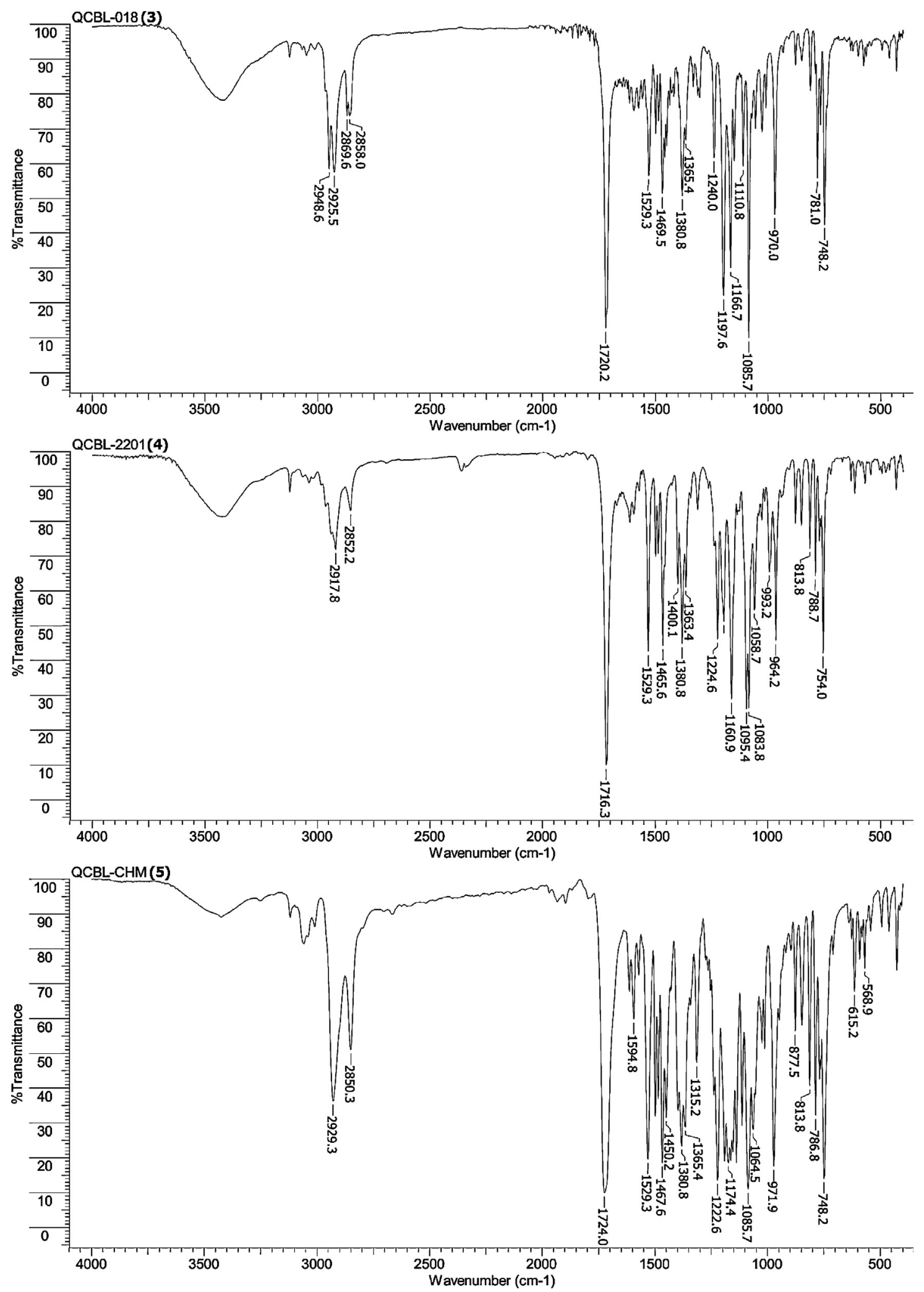

Fig. 5. FT-IR spectra for compounds 3-5. 